\title{
BIBECHANA
}

ISSN 2091-0762 (Print), 2382-5340 (Online)

Journal homepage: http://nepjol.info/index.php/BIBECHANA

Publisher: Department of Physics, Mahendra Morang A.M. Campus, TU, Biratnagar, Nepal

\section{Thermal properties of normal and sickled hemoglobin protein}

\author{
Jhulan Powrel ${ }^{1,2}$, Narayan P. Adhikari ${ }^{2 *}$ \\ ${ }^{1}$ Department of Physics, Butwal Multiple Campus, Tribhuvan University, Nepal \\ ${ }^{2}$ Central Department of Physics, Tribhuvan University, Kirtipur Kathmandu, Nepal \\ *Email: narayan.adhikari@cdp.tu.edu.np
}

Article Information:

Received: June 29, 2020

Accepted: August 2, 2020

Keywords:

Thermodynamic properties

Sickle cell

Molecular dynamics

Hemoglobin protein

\begin{abstract}
Thermodynamic properties of sickled and normal hemoglobin protein are considered within the framework of classical molecular dynamics. Here we have studied the specific heat capacity and RMSD (Root Mean Square Deviation) of both types of hemoglobin protein. Our investigation reveals that the specific heat capacity and RMSD for oxygenated hemoglobin protein is higher than those of de-oxygenated sickle hemoglobin protein. It is also observed that the specific heat capacity and RMSD values of sickle hemoglobin protein decrease with rise in temperature.
\end{abstract}

DOI: https://doi.org/10.3126/bibechana.v18i1.29750

This work is licensed under the Creative Commons CC BY-NC License. https://creativecommons.org/licenses/by-nc/4.0/

\section{Introduction}

Hemoglobin is the blood component consisting of heme and globin, where heme is the prothestic group containing iron and globin is the protein compound. It is responsible for the transportation of oxygen throughout the human body. Heme is synthesized by mitochondrion which is fixed with iron. Heme is protected by the surrounded globin protein. Each single hemoglobin molecule has two globin chains, one globin chain is $\alpha$ and the other is $\beta$. Two hemoglobin molecules combine to produce a functional tetramer. In inherited hemoglobin the amino acid sequence is changed because of the incorrect DNA code $(\mathrm{HbS})$. Such a cell having abnormality is a sickle cell. Sickle cell disease is the genetic disorder in which sudden change of hemoglobin protein occurs. The glutamic acid of both the $\beta$ chain in the sixth position of normal hemoglobin protein is replaced by valine in the sickle hemoglobin which is shown in Figure 1. As a result RBC changes from flexible bi-concave to strong elongated shape. Thus by carrying less oxygen, the hemoglobin becomes fibrous aggregations giving the entire red blood cell a sickle shape. Sickled hemoglobin protein (HbS) damages the sickle erythrocyte and causes the increase 
in the density, reduction in the deformability and increase in the adhesivity which shortens the life span [1-3]. The polymerization of deoxygenated hemoglobin $(\mathrm{HbS})$ is the primary and indispensable event in the molecular pathogenesis of sickle cell disease. There are many symptoms like the attacks of pain, sickle cell anemia, swelling in the hands and feet, bacterial infections and stroke. Longterm pain may develop as people get older because of sickle cell anemia. On the other hand, heterozygote for the sickle gene are relatively protected against the danger of dying by malaria, as now firmly established through a number of clinical field studies from different parts of Africa and Asia(Terai region of Nepal)[4].

Figure 2(a) shows the glutamate 6 of $\alpha$ chain in hemoglobin protein which is undergoes a mutation to valine. This mutation changes the charge on the surface of hemoglobin. The mutant protein is called sickle cell hemoglobin $(\mathrm{HbS})$. Valine residue 6 of the $\beta$ chain of deoxy-HbS lies on the surface of the protein. This hydrophobic residue, present in each of the $\beta$ chain, forms a hydrophobic contact in the neighboring $\beta$ chain of another hemoglobin molecule $[1,6]$. Figure 2(b) shows the mutation that replaces a glutamate residue by a valine residue which reduced the solubility of the protein.

Luzzatto L. studied the structural abnormality of sickle hemoglobin $(\mathrm{HbS})$ and noticed as this was the first time that a single amino acid replacement in a protein causes a serious disease [7]. A group of scientists, Stradner and

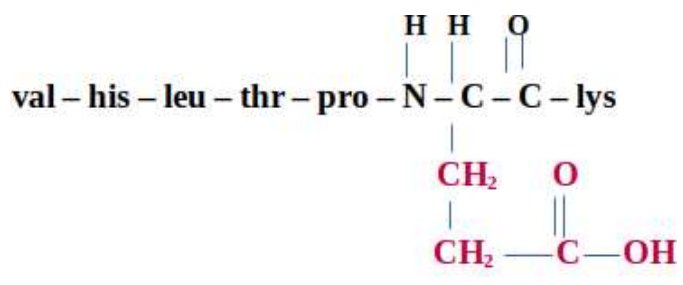

glu co-worker studied molecular dynamical simulations [1] and developed the concept of the study from soft matter physics to complex protein mixtures [8].A potential antisickling drug is still to be discovered [9] as per pathophysiological study in the last 100 years of sickle cell disease. Another group, Xianqiao Wang and Rodney D. developed a virtual mechanical model for determining the mechanical and thermal behavior of different soft matter by using the steps of optimization of energy, making of equilibration in the system and production run [10]. An electrochemistry based study designed a technique to control and monitor the polymerization of sickle-cell hemoglobin ( $\mathrm{HbS}$ ) by looking the change in turbidity during the depletion of oxygen in a small volume of custom-built thinlayer electrochemical cell. The cell allowed the investigation of $\mathrm{HbS}$ polymerization as a function of $\mathrm{HbS}$ concentration, temperature and solution $\mathrm{pH}$ [11].

Due to bad impact of sickle cell disease, this research work got attention on the study of thermal and transport property of sickle hemoglobin and normal hemoglobin protein. Literature review also reveals that the mechanical, thermal and transport properties of normal hemoglobin and sickle hemoglobin protein around human body temperature (310 $\mathrm{K})$ are not studied yet.

The paper is organized with methods and methodology part in section 2 , computational simulation part in section 3, results with discussion in section 4 and finally the conclusions at the last.

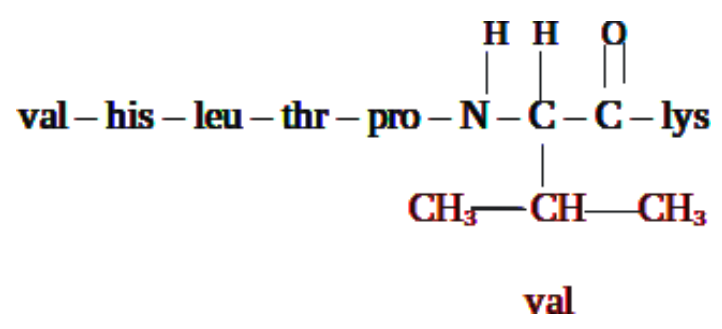

Fig. 1: Normal (glu) and sickle cell (val) hemoglobin [5]. 

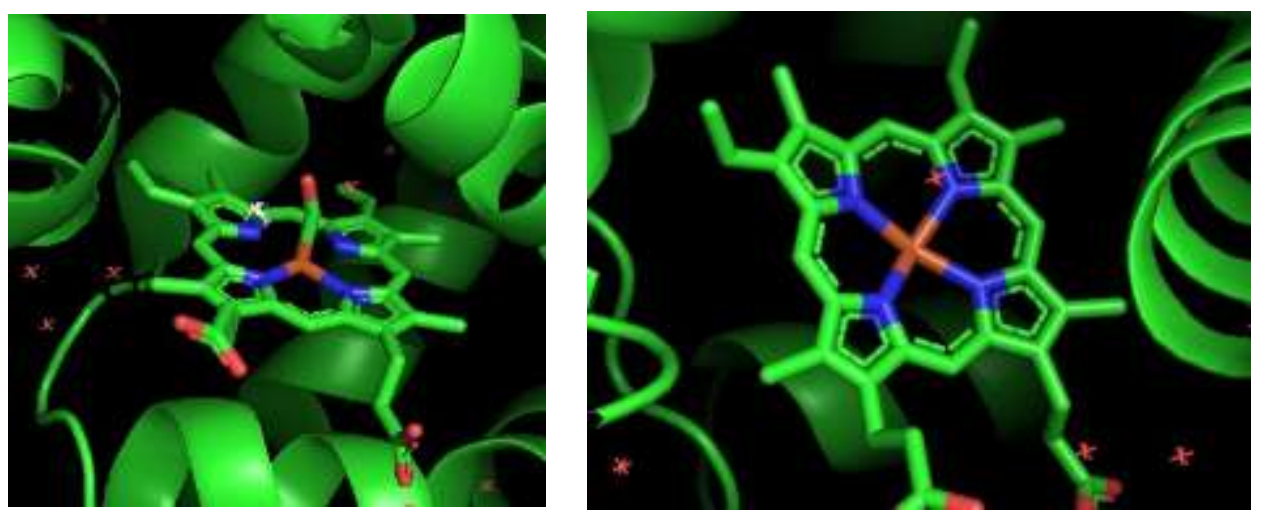

Fig. 2: (a) Normal hemoglobin with glutamic acid in $6^{\text {th }}$ position of beta chain (left) and (b) Sickle hemoglobin protein with valine in the 6 th position of beta chain (right).

\section{Methods and Methodology}

\section{Theory}

In molecular dynamics (MD), a hemoglobin protein molecule is considered inside the water for simulation. Protein is the combination of a number of atoms which behaves as pair-wise interaction in between two atoms in the molecule [12]. Each pair of atoms is interacted by bonded and nonbonded potentials. The molecular dynamic simulation calculates the motion of the atoms in molecules using Newtonian dynamics. In standard molecular dynamics simulations the forces may come from classical inter atomic potentials [13]. The non-bonded van der Waals and electrostatic are the interactive forces among the particles in the hemoglobin molecules. The total potential is obtain as,

$\mathrm{V}_{\text {total }}=\left[\mathrm{V}_{\text {bonded }}\right]+\left[\mathrm{V}_{\text {nonbonded }}\right]$

Or,

$\mathrm{V}_{\text {total }}=\left[\mathrm{V}_{\text {bond }}+\mathrm{V}_{\text {angle }}+\mathrm{V}_{\text {improper }}+\right.$

$$
\left.\mathrm{V}_{\text {proper }}\right]+\left[\mathrm{V}_{\mathrm{LJ}}+\mathrm{V}_{\text {coloumb }}\right]
$$

$$
V_{\text {bond }}\left(r_{i j}\right)=\frac{1}{2} K_{i j}^{b}\left(r_{i j}-b_{i j}\right)^{2} .
$$

where $K_{i j}^{b}$ force is constant, $r_{i j}$ is separation between the two bounded particles and $b_{i j}$ is the equilibrium bond length. Again the bond angle potential is written as,

$V_{\text {angle }}\left(\theta_{i j}\right)=\frac{1}{2} K_{i j k}^{\theta}\left(\theta_{i j k}-\theta_{i j k}^{0}\right)^{2}$

where $\theta_{i j k}, \theta_{i j k}^{0}$ and $K_{i j k}^{\theta}$ are the bond angle, equilibrium bond angle and the force constant respectively. Now the improper dihedral potential energy is,

$V_{\text {improper }}\left(\xi_{i j k l}\right)=\frac{1}{2} K_{\xi}\left(\xi_{i j k l}-\xi_{0}\right)^{2}$

where $\xi_{0}$ is the equilibrium improper angle and $K_{\xi}$ is the constant. Similarly the dihedral potential is,

$V_{\text {proper }}\left(\phi_{i j k l}\right)=\frac{1}{2} K_{\phi}\left(1+\cos \left(n \phi_{i j k l}-\phi_{s}\right)\right)$

where $\phi_{i j k l}$ is the proper dihedral angle, $\phi_{s}$ is an angle at which the potential is maximum, $\mathrm{n}$ is the multiplicity and $K_{\phi}$ is the barrier height.

Now the bond stretching potential is given by, 
Although Lennard-Jones potential(L-J) is not suitable for system where strong localized bonds may form (as in covalent system) or there is a delocalized electron sea where the ions remain (as in metals), the L-J potential helped us to understand basic points in many areas of condensed matter physics. The L-J potential for interaction between a pair of atom is given by [14],

$V_{L j}=4 \varepsilon\left[\left(\frac{\sigma}{r}\right)^{12}-\left(\frac{\sigma}{r}\right)^{6}\right]$

where $\varepsilon$ is the depth of the attractive well, $\sigma$ refers to the inter-particle distance and defines the strength of the interaction where the potential changes sign and $r$ defines the length scale. The Coulomb electrostatic interaction between two point charges $q_{i}$ and $q_{j}$ is defined by Coulomb potential as,

$V_{\text {Coloumb }}=\frac{q_{i} q_{j}}{4 \pi \varepsilon_{m} r^{2}}$

Root Mean Square Deviation (RMSD):

RMSD is the level of equilibration and gives the deviation of the molecules from the defined position in space. It also gives the idea of occurrence of the reaction in chemical bonding. The larger the deviation from mean position less will be the stability of the system. RMSD values are calculated for all atoms of the hemoglobin protein backbone for the entire protein and for the protein excluding the last five residues[15], which is the numerical measure of the structural difference of two states given by,

$R M S D\left(t_{j}\right)=\sqrt{\frac{\sum_{\alpha=1}^{N_{\alpha}}\left(\vec{r}_{\alpha}\left(t_{j}\right)-\left\langle\vec{r}_{\alpha}\left(t_{j}\right)\right\rangle\right)^{2}}{N_{t}}}$

With

$\left\langle\vec{r}_{\alpha}\left(t_{j}\right)\right\rangle=\frac{1}{N_{t}} \sum_{j=1}^{N_{t}} \vec{r}_{\alpha}\left(t_{j}\right)$

where $\mathrm{N}_{\alpha}$ is the number of atoms whose positions are compared, $\mathrm{N}_{\mathrm{t}}$ is the number of time steps over which atomic positions are compared, $\overline{\overrightarrow{r_{\alpha}}}\left(t_{j}\right)$ is the position of atom $\alpha$ at time $t_{\mathbf{j}}$ and $\left\langle\vec{r}_{\alpha}\left(t_{j}\right)\right\rangle$ is the average value of the position of atom to which the positions $\overrightarrow{\overrightarrow{r_{\alpha}}}\left(t_{j}\right)$ are being compared[15].

Specific heat Capacity:

The specific heat capacity is the amount of heat required for raising the temperature of an object per degree of temperature increase per unit mass. Thus in canonical ensemble the specific heat capacity is [16],

$c_{v}=\frac{\left\langle E_{B}^{2}\right\rangle-\left\langle E_{B}\right\rangle^{2}}{\mathrm{k}_{\mathrm{B}} \mathrm{T}^{2}}$

where $\left\langle E_{B}\right\rangle^{2}$ is square of the average of the total energies and $\left\langle E_{B}{ }^{2}\right\rangle$ is the average of the square of the total energy and $k_{B}$ the Boltzmann constant.

\section{Computational details}

The proposed research is designed for working in theoretical computational method using molecular dynamics. Hemoglobin protein of sickle and normal cell are obtained from the RCSB (Research Collaboratory for Structural Bioinformatics).org in PDB (Protein Data Bank) form and then simulation is completed using NAMD (NAno scale Molecular Dynamics) and VMD (Visual Molecular Dynamics) software by following the steps of structure making, energy minimization and making of equilibration in the system. After performing various simulation steps the output data are used for the calculations of RMSD and specific heat capacity of both of the hemoglobin protein. For this simulation six systems are designed with four molecules which are then solvated with water using charmm force field (CHARMM 36) under following parameters: A system of oxygenated hemoglobin protein (a3n) with 4546(without water) atoms under the interaction of the bond potential and non- 
bonded potential inside a box with cut off distance of $12.0 \AA$, pressure of 1 bar and temperature $310 \mathrm{~K}$. A system of oxygenated hemoglobin protein(e83) with 19167(without water is 4668) atoms under the interaction of the bond potential and non-bonded potential inside a box with cut off distance of $12.0 \AA$, pressure of 1 bar and temperature $310 \mathrm{~K}$. A system of oxygenated hemoglobin protein(uvx) with 1863 atoms under the interaction of the bond potential and nonbonded potential inside a box with cut off distance of $12.0 \AA$, pressure of 1 bar and temperature $310 \mathrm{~K}$. Similarly, for other three systems of sickle hemoglobin protein $(\mathrm{HbS})$ there are 9112 atoms in each and interacting at the same potential as before with pressure at 1 bar, cut off distance of $12.0 \AA$ and at temperatures of $305 \mathrm{~K}, 310 \mathrm{~K}$ and $315 \mathrm{~K}$. After equilibration of all the above six system they are energetically minimized at their corresponding constant temperature which provides their RMSD values. At last systems are further modified for NVE and NVT simulation run in which we use the temperature coupling feature of NAMD to set the temperature of the molecules in the outer layer of the sphere to $300 \mathrm{~K}$, while the rest of the bob is set to temperature of $330 \mathrm{~K}$.

\section{Result and Discussion}

Present work was to study the RMSD as well as specific heat capacity of normal and sickle hemoglobin protein. The RMSD was calculated using the equation (9).

We plotted the RMSD of hemoglobin protein against the time steps as follows; where Figure 3(a) and 3(b) indicates the graph of root mean square deviations of oxygenated sickle hemoglobin protein and de-oxygenated hemoglobin protein at temperature of $310 \mathrm{~K}$ and obtained the RMSD as $0.8 \AA$ and 1.25 $\AA$ respectively. They were found to be increased initially with small fluctuation and then remain constant for both at various values, i.e. the RMSD of deoxygenated hemoglobin found to be higher than of oxygenated sickle hemoglobin protein.

RMSD plot of other system of hemoglobin protein were also plotted where Figure 4(a) and 4(b) indicates the root mean square deviations of oxygenated hemoglobin protein and sickle hemoglobin protein at temperature of $310 \mathrm{~K}$ For which the RMSD found to be increased initially with small fluctuation and then remain constant for both at various values of $1.3 \AA$ and $0.75 \AA$ respectively, i.e. the RMSD of oxygenated hemoglobin is higher than of sickle hemoglobin protein.

Similarly, RMSD for sickle hemoglobin protein at various temperatures were studied, where Figure 5(a) and 5(b) indicating the root mean square deviations of sickle hemoglobin protein at $305 \mathrm{~K}$ and $315 \mathrm{~K}$ respectively. They are increased initially with small fluctuation and then remain constant for both at various values of $1.5 \AA$ and $1.4 \AA$ respectively i.e. the RMSD of sickle hemoglobin protein at lower temperature is higher than of sickle hemoglobin protein at higher temperature. The above Figure 3(a), 3(b), 4(a) and 5(a), are the RMSD graph at $310 \mathrm{~K}$ for carbon monoxy-hemoglobin(s), deoxygenated hemoglobin protein, truncated heme-ligand hemoglobin and sickle hemoglobin protein respectively. Correspondingly their RMSD were estimated as $0.8 \AA, 1.2 \AA, 1.3 \AA$ and $0.75 \AA$, i.e. the RMSD of sickle hemoglobin is least $(0.75 \AA)$ and of truncated ligand hemoglobin is $\operatorname{maximum}(1.3 \AA)$. Thus, deoxygenated sickle hemoglobin with fibrous nature shows least deviation from the mean position, whereas of truncated ligand hemoglobin with large no of hydrogen bond and hydrophobic potential move faster with more RMSD value. Similarly normal oxygenated and deoxygenated hemoglobin 
have their RMSD $1.3 \AA$ and $1.25 \AA$ respectively which are higher than both the oxygenated $(0.8 \AA)$ and deoxygenated sickle hemoglobin $(0.75 \AA)$. Again at temperatures of $305 \mathrm{~K}, 310 \mathrm{~K}$ and $315 \mathrm{~K}$ (Figure 4(b), 5(a) and Figure.5 (b)) of deoxygenated sickle hemoglobin (HbS) [17] the RMSD are $1.5 \AA, 0.75 \AA$ and $1.4 \AA$ respectively.

Figure 6(a) and 6(b) are energy fluctuation and energy distribution graph during NVE and NVT run. They gives the energy deviation from the mean [Fig 6(a)] and energy distribution pattern [Fig 6(b)] i.e. more the energy more is the velocity as well as temperature of the system of particles and hence system of protein behaving as thermometer. Computationally by using NAMD code the average of square of the total energies and square of the average total energy of de-oxygenated hemoglobin protein(e83) were obtain as 6722047.08 $\mathrm{kcalmol}^{-1}$ and $6714152.23 \mathrm{kcalmol}^{-1}$ respectively. On using these values the specific heat capacity of de-oxygenated hemoglobin protein was estimated as 2903 $\mathrm{Jkg}^{-1} \mathrm{C}^{-1}$ (Table 1). Now for the calculation of specific heat capacity $\left(\mathrm{C}_{\mathrm{v}}\right)$, we have used the following theoretical and simulation parameters under the assumption of classical molecular dynamics: $\mathrm{k}_{\mathrm{B}}=0.00198657 \mathrm{kcal} / \mathrm{mol}$ $\mathrm{K}, \sigma \sim 8 \mathrm{~K}, \mathrm{~T}=317 \mathrm{~K}, \mathrm{~J}=1.43846 \times 10^{20}$ $\mathrm{kcal} / \mathrm{mol}$.

The specific heat capacity of normal and sickle hemoglobin protein were calculated by using the equation (11) and are tabulated in Table 1 and Table 2 for all the six systems. The average specifjc heat capacity of sickle hemoglobin $\quad\left(\frac{2527+1966+1227}{3}=1906.67 \quad \mathrm{~J} / \mathrm{kg}-\mathrm{C}\right.$ [Table 1]) was less than of normal hemoglobin's (3587 J/kg-C， $2903 \mathrm{~J} / \mathrm{kg}-\mathrm{C}$ and $3204 \mathrm{~J} / \mathrm{kg}-\mathrm{C}$ ) [Table:2].
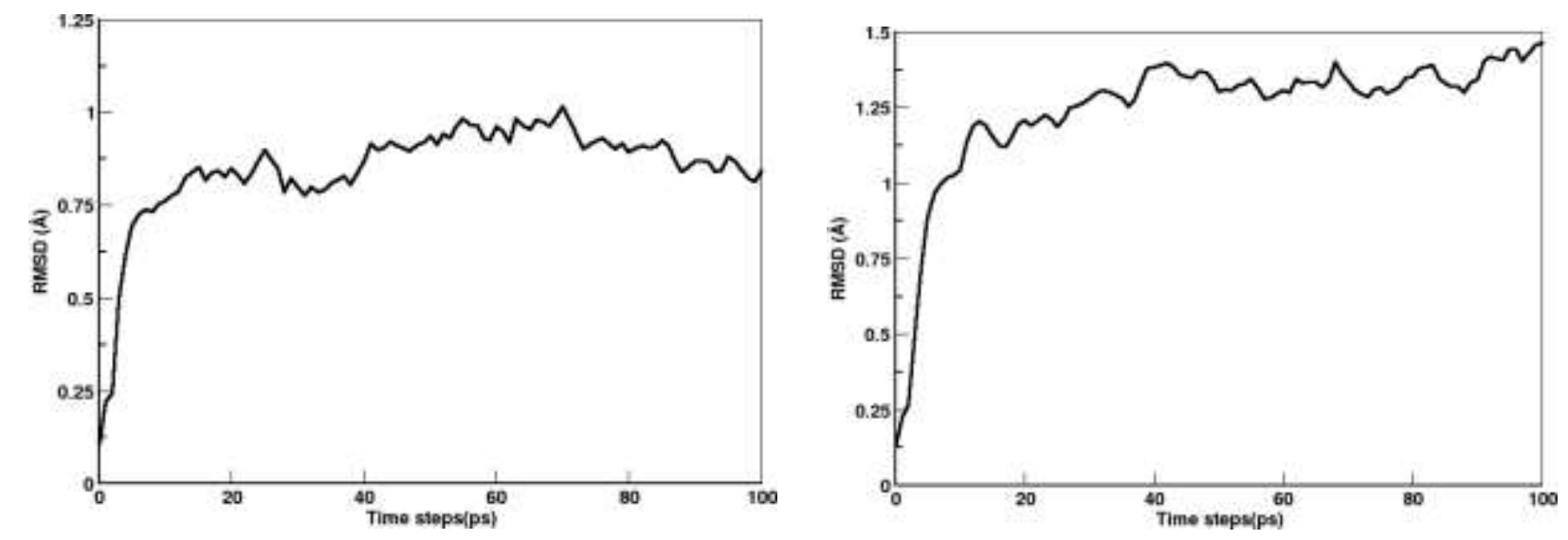

Fig. 3: (a) RMSD graph of oxygenated sickle hemoglobin protein (left). (b) RMSD graph of deoxygenated hemoglobin protein (right). 

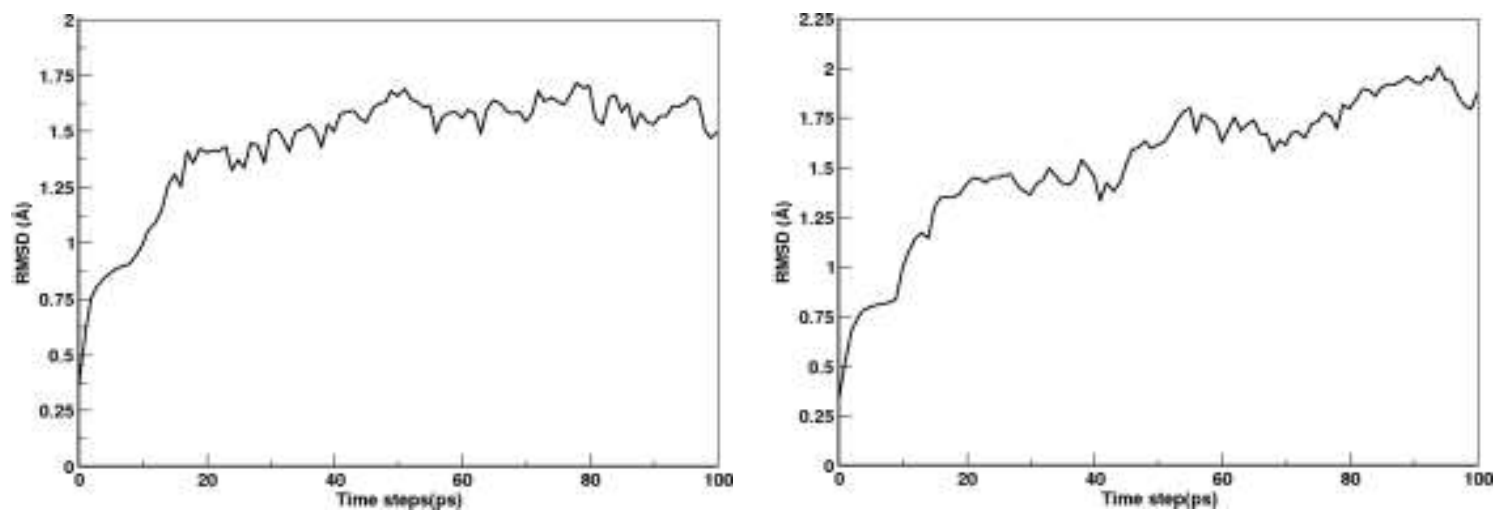

Fig. 4: (a) RMSD graph of oxygenated hemoglobin protein (left). (b) RMSD graph of sickle hemoglobin protein (right).
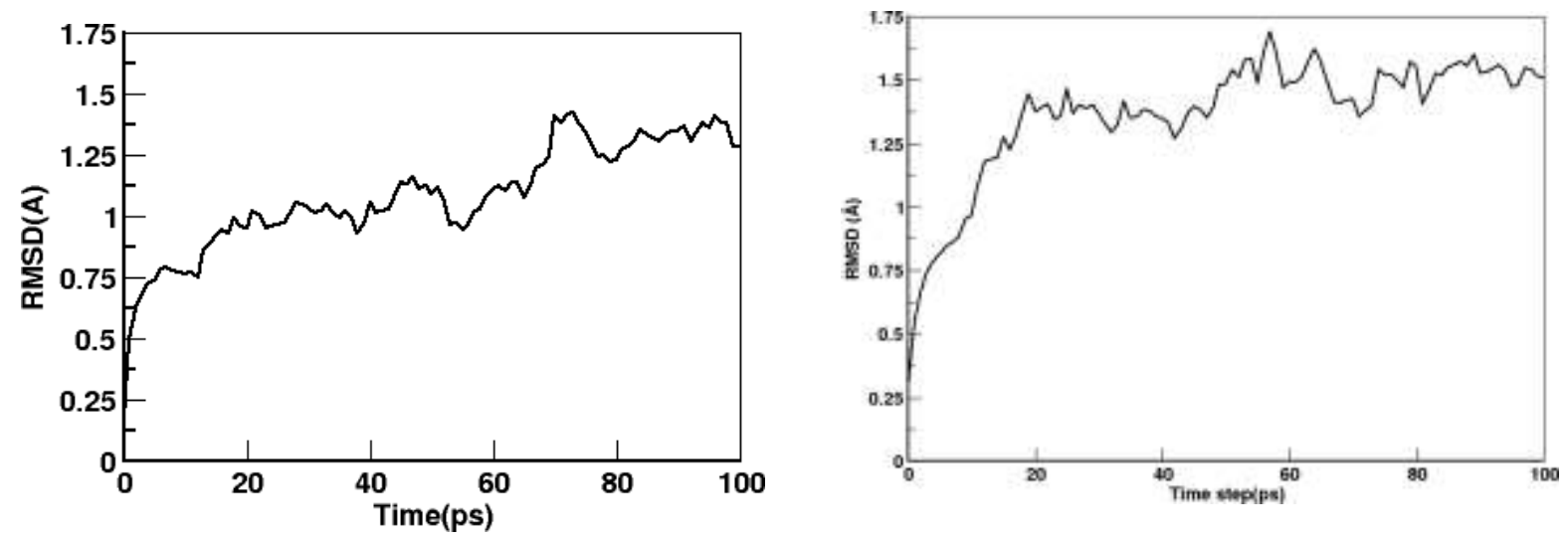

Fig. 5: (a) RMSD graph of sickle hemoglobin protein at $305 \mathrm{~K}$ (left). (b) RMSD graph of sickle hemoglobin protein at $315 \mathrm{~K}$ (right).
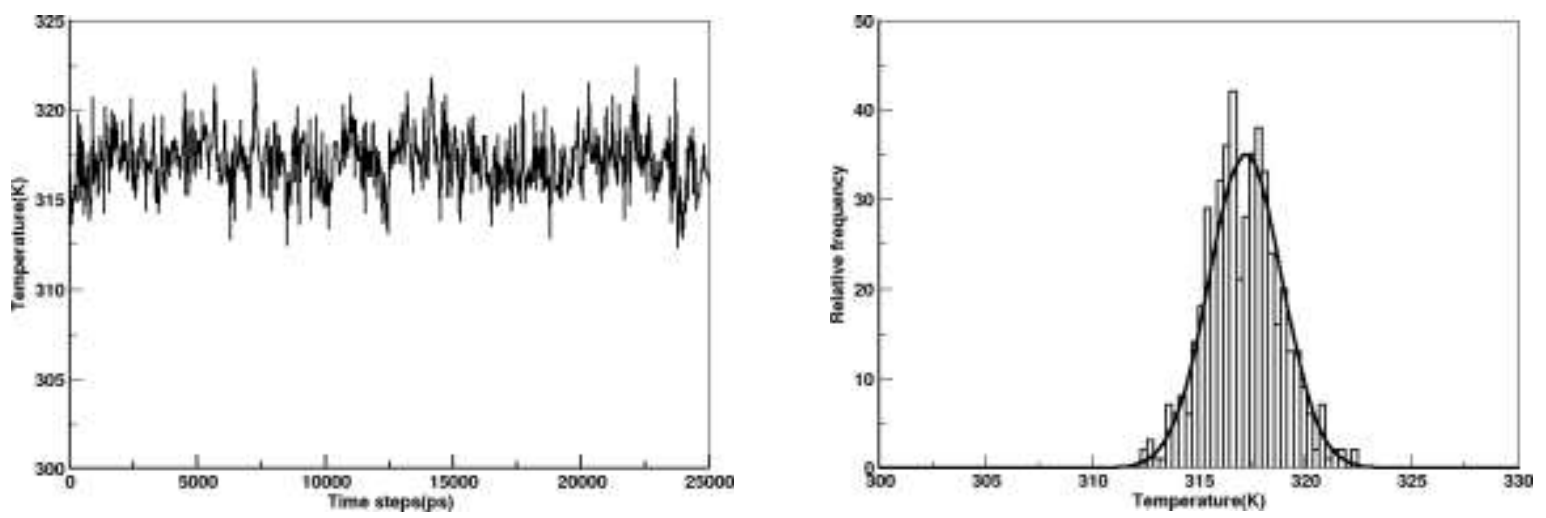

Fig. 6: (a) Energy flocculation of de-oxygenated hemoglobin protein (b) Maxwell energy distribution for de-oxygenated hemoglobin protein. 
Table 1: For normal and sickle cell hemoglobin protein at $310 \mathrm{~K}$ of temperature.

\begin{tabular}{|c|c|c|}
\hline For & $\mathbf{R M S D}(\AA)$ & $\mathbf{C}_{\mathbf{v}}\left(\mathbf{J k g}^{\mathbf{1}} \mathbf{C}^{\mathbf{- 1}}\right)$ \\
\hline Oxygenated sickle hemoglobin protein) & 0.8 & 3587 \\
\hline De-oxygenated hemoglobin protein & 1.25 & 2903 \\
\hline Oxygenated hemoglobin protein & 1.3 & 3204 \\
\hline Sickle hemoglobin protein(2hbs) & 0.75 & 1966 \\
\hline
\end{tabular}

Table 2: For sickle cell hemoglobin protein (2hbs) at different temperature.

\begin{tabular}{|c|c|c|c|}
\hline For & Temp.(K) & $\mathbf{R M S D ( \AA )}$ & $\mathbf{C}_{\mathbf{v}}\left(\mathbf{J k g}^{-\mathbf{1}} \mathbf{C}^{-\mathbf{1}}\right)$ \\
\hline Sickle hemoglobin protein(2hbs) & 305 & 1.5 & 2527 \\
\hline Sickle hemoglobin protein(2hbs) & 310 & 0.75 & 1966 \\
\hline Sickle hemoglobin protein(2hbs) & 315 & 1.4 & 1227 \\
\hline
\end{tabular}

\section{Conclusion and Concluding Remarks}

The RMSD of normal and sickle hemoglobin protein was calculated within $0.75 \AA$ to $1.5 \AA$ which indicates that the proposed system is in the valid range $(<4 \AA)$ for molecular dynamical study. This study also reveals that the $\mathrm{HbS}$ at $305 \mathrm{~K}$ is most unstable ( $\mathrm{RMSD}=1.5 \AA$ ) among the considered system. The RMSD and specific heat capacity $\left(\mathrm{C}_{v}\right)$ of de-oxygenated hemoglobin protein at $310 \mathrm{~K}$ are estimated as $1.25 \AA$ and 2903 $\mathrm{J} / \mathrm{kg}-\mathrm{C}$ [Table 1] respectively. It also obvious that the de-oxygenated hemoglobin protein (average value $=1906.67 \mathrm{~J} / \mathrm{kg}-\mathrm{C}$ ) has lower specific heat capacity than oxygenated (first three $\mathrm{C}_{v}$ of Table 1). It shows that at higher $(315 \mathrm{~K})$ temperature above $310 \mathrm{~K}$ the RMSD of sickle hemoglobin protein is increased due to less polymerization (sickling) of protein but increased in RMSD at lower temperature $(305 \mathrm{~K})$ is still not understood.
We found essentiality of additional research work on the free energy calculation along with the mechanical and transport properties of sickle hemoglobin protein for its depth knowledge.

\section{Acknowledgments}

JP acknowledges UGC, Nepal for providing financial support (Grant No. S\&T-13-75/76) and Butwal Multiple Campus, Butwal (Tribhuvan University) for providing $\mathrm{Ph}$. D. leave. This work is also under the grant of UGC, Nepal for which NPA acknowledges the UGC Award no. CRG-73/74-S\&T-01.

\section{References}

[1] A. Stradner et al, New insight into cataract formation â enhanced stability through mutual attraction, Physics Department and Fribourg Center for Nanomaterials, University of Fribourg, $\mathrm{CH}-$ 1700 Fribourg, Switzerland (2007). 
[2] W. A. Eaton and J. Hofrichter, Sickle cell hemoglobin polymerization, Advances in Protein Chemistry 40 (1990) 63-279. http://doi.org/10.1016/s0065-3233(08)60287-9.

[3] F. Ferrone, R. L. Nagel, Sickle hemoglobin polymerization. In: Disorders of hemoglobin: Genetics, pathophysiology, clinical management, Steinberg $\mathrm{MH}$, Forget BG, Higgs D, Nagel RL (Eds), Cambridge University Press (2000).

[4] Luzzatto, Lucio., Sickle cell anaemia and malaria, Mediterranean Journal of Hematology and Infectious Diseases (4)1 (2012) e2012065. http://doi.org/10.4084/MJHID.2012.065.

[5] D. C. Rees, T. N. Williams, M. T. Gladwin, Sickle-cell disease, The Lancet 376(9757) (2010) 2018-2031.

[6] J. Robert, J. Ouellette, David Rawn, Organic Chemistry (Second Edition) Structure, Mechanism, Synthesis (2018) pp. 929-971.

[7] W. D. Callister, Materials Science and Engeenering, An Introduction, John Wiley Sons.Inc. US, (2007).

[8] Retrieved Sept. 22th, 2018 from www.google.com/Sickle Cell Anemia.

[9] Mahran et al., Beni-Suef University Journal of Basic and Applied Sciences, Springer open, Egypt (2019). https : //doi.org/10.1186/s43088-019-0016-x

[10] Wang Xianqiao and D. Rodne, Avereabtt Molecular dynamics simulations indicate that deoxyhemoglobin, oxyhemoglobin, carboxy-hemoglobin, and glycated haemoglobin hemoglobin under compression and shear exhibit an anisotropic mechanical behavior, Sumith Yesudasan ORCID Icon (2017)1417-1429.

https://doi.org/10.1080/07391102.2017.1323674.

[11] Iqbal, Zeshan et al., Investigation of sickle-cell polymerisation under electrochemical control, Chemphyschem: A European Journal of Chemical Physics and Physical Chemistry 14 (10) (2013) 2143-8. https://doi.org/10.1002/cphc.201300203.

[12] G. R. Serjeant, Sickle-cell disease. The Lancet 350(9079) (1997) 725-730

[13] M. P. Allen and D. J. Tildesley., Computer Simulation of Liquids, Oxford University Press, New York (1987).

[14] D. Frenkel, B. Smit, Understanding Molecular Simulation From Algorithms to Applications $2^{\text {nd }}$ ed; Academic Press; San Diago, USA (2002).

[15] C. James Phillips, Rosemary Braun, Wei Wang, James Gumbart, Emad Tajkhorshid, Elizabeth Villa, Christophe Chipot, Robert D. Skeel, Laxmikant Kale, and Klaus Schulten. Scalable molecular dynamics with NAMD. Journal of Computational Chemistry 26 (2005)1781-1802. www.ks.uiuc.edu/Training/Tutorials(RetrivedonJu ne10th2020

[16] K. Huang, Statistical Mechanics, John Wiley \& Sons, New York (1987).

[17] J. C. Phillips et al., Scalable molecular dynamics with NAMD, J. Comp. Chem. 26 (2005) 17811802 . 